\title{
Going Beyond Equations With Disciplinary Thinking In First-Year Physics
}

\author{
M. Qasim Syed, Mount Royal University, Canada
}

\begin{abstract}
Students in first-year physics courses generally focus on hunting for suitable equations and formulas when tackling a variety of physical situations and physics problems. There is a need for a framework that can guide them to disciplinary ways of thinking and help them begin to think like physicists. To serve this end, in this study, a framework of disciplinary thinking in physics was presented to the students and incorporated in the delivery of a first-year course on electricity and magnetism for engineering students. The framework consisted of three types of thinking: principlebased thinking (PBT), case-based thinking (CBT), and experiential-intuitive thinking (EIT). The students' experiences of learning this framework were tracked through weekly reflection reports, which were analyzed using a coding scheme comprised of the following four categories of increasing cognitive complexity for each type of thinking: mentioning the type of thinking learned without elaboration (code A), mentioning the type of thinking learned with elaboration (code B), applying the type of thinking learned (code $C$ ) and making meaning of the type of thinking learned (code D). Examples of students' reflections for these codes for each type of thinking are included. The students most predominantly reflected on PBT followed by CBT with a very few reflections on EIT. Within both PBT and CBT, most reflections fell under the code B. Overall, the results are encouraging and point to a students' shift from formula hunting to the thinking framework based strategies.
\end{abstract}

Keywords: Disciplinary Thinking; First-Year Physics; Going Beyond Equations; Thinking Like a Physicist; Principle-based Thinking; Case-based Thinking; Electricity and Magnetism

\section{INTRODUCTION}

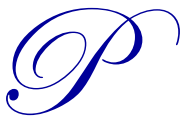

hysics is a beautiful subject that is at the heart of understanding how the physical world around us works. It also forms the basis of various branches of engineering and technology. It has engaged great minds like Newton, Einstein and Feynman. Yet, most first-year students do not find physics exciting, enjoyable or fun as physicists do; rather, they find physics to be challenging (Oliveira \& Oliveira, 2013; Ornek, Robinson, \& Haugan, 2008) and difficult to apply in explaining real life phenomena (Moore, 2011). In solving physics problems, students generally remain focused on searching for suitable physics formulas and concentrate on manipulating them to calculate the unknown physical quantity (Ellis \& Turner, 2003; Gire, Jones, \& Price, 2009; Sherin, 2001; Walsh, Howard, \& Bowe, 2007). This approach can partly be attributed to the lack of student engagement in a traditional passive lecture and the resulting difficulty in understanding the physics content. The ineffectiveness of a traditional lecture in which students were not active participants, regardless of the experience or the skill of the instructor in addressing the learning goals of a first-year physics course, has been well documented (McDermott, 1993; Oliveira \& Oliveira, 2013). Physics educators have made great strides in tackling student difficulties with the content through a variety of methods involving interactive engagement such as Just-inTime-Teaching (JiTT; Novak, Gavrin, \& Wolfgang, 1999), the Peer Instruction method (Derek Bok Center, 2007; Dufresne, Gerace, Leonard, Mestre, \& Wenk, 1996; Mazur, 1997), and the laboratory-based curriculum called Physics by Inquiry (McDermott, Shaffer, \& Constantinou, 2000; Lindsey, Hsu, Sadaghiani, Taylor, \& Cummings, 2012). The effectiveness of these interactive methods in enhancing understanding of the content has been established through various studies (Crouch \& Mazur, 2001; Fagen, Crouch, \& Mazur, 2002; Hake, 1998; Lasry, Mazur, \& Watkins, 2008; McDermott, Heron, Shaffer, \& Stetzer, 2006; Meltzer \& Manivannan, 2002). Understanding the content is important, but does not necessarily mean that students think like physicists. For 
example, by interviewing students in a Cambridge University first-year physics course, Mahajan (2001) found that even the popular and effective peer-instruction method of Eric Mazur (1997) did not help the talented Cambridge students to think like physicists. There is, therefore, a need for a framework that can help students to go beyond equations and begin to think like physicists. Accordingly, in the current study, a framework of disciplinary thinking in physics was presented to first-year engineering students to fill this need. Students' experiences of learning the modes of thinking in this framework were tracked through weekly reflection reports. Results of the analysis of these reflections are presented in this paper.

\section{Disciplinary Thinking Framework}

Disciplinary thinking is composed of two elements: the structure of the content and the ways experts think about the content (Langer, Confer, \& Sawyer, 1993). Both of these vary from discipline to discipline-hence the term disciplinary thinking. For example, thinking in physics is different from thinking in history. The importance of developing disciplinary thinking in university students is well recognized (Pace \& Middendorf, 2004; Pintrich, 2004). In fact, disciplines are considered to constitute the most refined ways yet developed for thinking about and investigating issues that have long fascinated and perplexed thoughtful individuals (Gardner \& Boix-Mansilla, 1994). In a typical first-year physics course, traditionally the emphasis is on the content and the ways of thinking about that content generally remain tacit (Nersessian, 1995). In this study, essential ways of thinking in physics were identified and incorporated into a disciplinary thinking framework that was presented to the students as an integral part of the course.

To establish the framework, a literature survey was carried out. The resulting framework that was presented to students is based on the following three broad ways of thinking, namely: principle-based, case-based and experiential-intuitive. (Hestenes 1987; Schuster \& Undreiu 2009; Schuster, Undreiu \& Adams, 2007; Snyder, 2000; Undreiu, Schuster, \& Adams, 2008; Van Heuvelen, 1991). A brief description of these three ways of thinking is presented below.

\section{Principle-based Thinking (PBT)}

In this way of thinking, physics problems are solved or physical situations are understood by a systematic application of fundamental physics concepts and principles. Thus, the ability to decide upon the appropriate principles is strongly correlated with the ability to solve physics problems or understand physical situations. Even in the work of great scientists, the correctness of their predictions regarding a physical situation has depended on the appropriateness of the principles used in modeling the situation (e.g., see Lovatt \& Syed, 2014). The strength of this way of thinking is that many problems and situations can be tackled by application of a relatively few fundamental concepts and principles.

In applying PBT, important factors include: clarity of concepts and definitions, ability to make suitable assumptions (Fortus, 2009), understanding of the knowledge structure (Bagno, Eylon, \& Ganiel, 2000; FergusonHessler \& de Jong, 1987; Snyder, 2000), facility in employing multiple representations (Kohl \& Finkelstein, 2008) and dimensional analysis (Miller, 1952; Misic, Najdanovic-Lukic, \& Nesic, 2010; Pescetti, 2008). In some situations, multiple graphing techniques are also useful, and can enhance appreciation of the different features of the data related to a problem (Syed \& Lovatt, 2014). Essential steps in solving a physics problem by PBT comprise of turning the description of the problem into relevant multiple representations (pictorial, physical, graphical and mathematical) and using them to obtain the answer (Van Heuvelen, 1991). A quick check on the answer can be made by doing the order of magnitude calculations.

\section{Case-based Thinking (CBT)}

This is an associative way of thinking that is based on the use of past experience to understand and solve new situations and problems (Kolodner, 1992; Schuster \& Undreiu, 2009). In this way, one applies knowledge of previous cases to new cases. This may mean a direct application if the new problem is very similar to a previous problem. Or, one has to adapt a previous solution to a new problem by accounting for the differences. There are two modes of applying CBT: Interpretive and problem solving. In the interpretive mode, one compares a new problem 
with a previous problem to understand or interpret the new problem. This mode is useful when the new problem seems a bit different on the surface but on a deeper level has the same underlying principle as the previous problem. In the problem solving mode, one generates a solution to a new problem based on the solution to a previous problem.

In essence, similarities in two situations or problems could be based on deep features (involving underlying principles and procedures) or surface features (involving objects, contexts, and quantities provided; Docktor, Mestre, \& Ross, 2012). Experts look for the similarities based on underlying principles and procedures, while novices focus more on the similarities based on surface features. Analogical thinking where one maps features of one domain to another domain is also considered a form of case-based thinking (Aamodt \& Plaza, 1994).

\section{Experiential-intuitive Thinking (EIT)}

This is a more spontaneous mode of thinking than a conscious mode of thinking and arises in situations related to everyday experiences. It can be approached from two different perspectives: misconceptions or phenomenological primitives (p-prims). Misconceptions are a stable and coherent or incoherent set of conceptions that students have coming into a physics course and they lead to systematic patterns of error (Vosniadou, 2002, cited in Leppävirta, 2012). For example, the acceleration of a positively charged particle at the highest point of a vertical motion in a downward electric field may be incorrectly considered to be zero due to the misconception that the acceleration of an object is zero when its velocity is zero.

P-prims refer to minimal abstractions from everyday experiences and work fairly well in situations close to experience, but may lead to error when applied inappropriately to a situation (Schuster \& Undreiu, 2009). Therefore, experts and novice students both may use this mode of thinking but produce vastly different results. An example of a commonly used p-prim is the Ohm's Law p-prim (diSessa, 1993). In general, this p-prim means more effort implies more result. It involves an agent, a resistance and a result; the stronger the agent, the greater the result, and the stronger the resistance, the weaker the result. This can be abstracted from any number of physical experiences, such as pushing objects. An example of its incorrect application is, while considering the electric forces on two point charges, students think that when the magnitude of the first charge is increased, the electric force on the second charge increases, leaving the force on the first charge unchanged because of ignoring the symmetry of electric forces (Leppävirta, 2012).

\section{CONTEXT}

The study was conducted in Fall 2010 with the students of ENGR 1215: Electricity \& Magnetism, a firstyear calculus-based course for engineering students at Mount Royal University, a midsize undergraduate university in Western Canada that is focused on teaching and learning informed by scholarship. Students are required to pass ENGR 1205: Statics and MATH 1217: Calculus for Engineers and Scientists-I before taking this course. Even though students have completed these prerequisites, they generally find this course difficult as electricity and magnetism deal with abstract concepts (e.g., fields, charge and current) that are not in their everyday experience (McDermott \& Schaffer, 1992; Miokovic, Ganzberger, \& Radolic, 2012; Pepper, Chasteen, Pollock, \& Perkins, 2010).

At the time of the study, the course had 3 hours of lecture, 1.5 hours of tutorial and a 2-hour lab per week. The tutorial was used as a problem solving session or a simulation activity session. Five computer simulation activities were incorporated into the course to enhance students' engagement and understanding of the content. The computer simulations were taken from the project "Modular Approach to Physics" (n.d.)."

\section{METHODOLOGY}

Near the beginning of the semester, the study was described to the students of ENGR 1215 and they were invited by the researcher to participate in the study. A faculty member from another department who was not associated with the study administered the consent forms in the absence of the researcher. The researcher did not have access to the forms until final grades had been submitted. Eighteen students registered in the course and all 
consented to participate in the study, though one student later dropped out from the course. Students had the option of withdrawing from the study until the last day of the final examination period by sending an e-mail to the faculty member who administered the consent forms, but no students withdrew from the study. The study had the approval of the Human Research Ethics Board of Mount Royal University.

Disciplinary thinking framework, mentioned earlier, was explained to the students and incorporated in the delivery of the course. The components of the course intended to help the students in learning and applying the framework included lectures, problem solving sessions, simulation activities, the textbook, quizzes, labs and tests (including the preparation for them).

To understand students' thinking coming into the course, the students were asked in the first class to submit a written response to the following question: Briefly explain how have you solved physics problems in the past? A slightly modified question (How do you solve physics problems?) was put on the final examination to gauge any shift in the students' thinking.

The students' experiences of developing disciplinary thinking were explored using weekly reflection reports that started in the third week of the semester and accounted for $10 \%$ of the course grade. The students had the option of supporting their narratives with diagrams, pictures or graphs or any other type of illustration. They were given the last five minutes of the last lecture of every week to work on their reflection reports. Generally they wrote the reflections earlier and used this time to put final touches on them. The reflection reports were generally graded weekly and returned. The criteria for marking the reports were clarity, thoroughness and creativity, but not correctness of the content. This approach helped students in sharing their experiences without fear of losing marks for being wrong. However, the reflection reports did provide an opportunity to give feedback on their performance both in terms of the physics content and the learning of the disciplinary ways of thinking.

For each reflection report, the students were asked to reflect on what they had learned in a given week in terms of disciplinary thinking and how they had learned it by answering the following questions.

1. What kind(s) of thinking (e.g., principle-based) did you learn this week?

2. Where (e.g., lecture) and how did you learn it? Illustrate your answer with at least one example.

3. Do you have any questions based on your responses in Questions 1 and 2?

These questions were inspired by another study on students' epistemologies and conceptual learning in physics by May and Etkina (2002).

All data sources were an integral part of the course and students were not asked to do any extra work for this study except signing the consent form. But for research purposes, only reports of the consenting students were to be used. This approach was adapted to ensure that all students benefitted from the activities of self reflection regardless of their participation in the study.

The data sources employed in this study were used to answer the following research questions:

1. How does the disciplinary thinking framework help students think beyond equations?

2. How does the disciplinary thinking framework help students in learning disciplinary ways of thinking?

\section{Coding Scheme and Data Analysis}

To seek out patterns in the students' ways of thinking from the weekly reflection reports, a coding scheme was developed. The coding scheme evolved from reading students' reflection reports several times. The coding scheme was based on two levels: general and specific. On the general level it included the three types of thinking mentioned under the heading Disciplinary Thinking Framework, namely principle-based thinking (PBT), case-based thinking (CBT) and experiential-intuitive thinking (EIT). On the specific level, each type of thinking was nested into four specific codes-A, B, C and D. Figures 1-3 show the specific codes for each type of thinking with corresponding sample quotes from the students' weekly reflection reports. The four specific codes for each type of 
thinking progressively reflect ascending levels of complexity of thinking; with code A representing the simplest and code D representing the most complex. The coding scheme reflects the spirit of Bloom's (1956) taxonomy of the cognitive domain of learning and its subsequent revision (Anderson et al., 2001). The revised taxonomy consists of the following six major categories starting from the simplest cognitive behavior and progressing to the most complex: remember, understand, apply, analyze, create, and evaluate. Incorporating the idea of increasing levels of complexity of thinking, the four categories developed in this study for categorizing the students' reflections are: mentioning the type of thinking learned without elaboration (code A), mentioning the type of thinking learned with elaboration (code B), applying the type of thinking learned (code C), and making meaning of the type of thinking learned (code D). In these categories, the phrase "the type of thinking" when applied to principle-based or casebased thinking also means any aspect(s) of these types of thinking as elaborated under Disciplinary Thinking Framework. These aspects have also been included in Figures 1 and 2. Also, it should be pointed out that the main difference between "mentioning with elaboration" and "applying" is that mentioning refers to students" comprehension of relevant information presented in a component of the course, while applying refers to episodes where students applied the learned ideas themselves to understand a physical situation or solve a problem. The highest category "making meaning" (code D) goes one step further than applying and involves factors like understanding or appreciating the significance of certain a type of thinking, or learning a broader lesson. A more complete list of these factors has been included in Figures 1-3.

As mentioned earlier, the coding scheme used has three types of thinking with four specific codes associated with each type of thinking; this means there are a total of 12 specific codes. In a student's reflection, each episode of a complete thought was assigned an appropriate code from these 12 specific codes. The total numbers of indications for each specific code (henceforth referred to as cumulative frequency for the specific code) for all the students covering all their reflections over the whole semester were counted. By adding the cumulative frequencies for the four specific codes within each type of thinking, the cumulative frequency $(f)$ for each type of thinking was obtained as shown in Figure 4. This figure also shows $f$ as the percentage of the sum of the cumulative frequencies of all three types of thinking. The cumulative frequency $\left(f^{\prime}\right)$ for each specific code within the three types of thinking is shown in Figure 5.

\section{RESULTS AND DISCUSSION}

From inspection of Figure 4, which shows the cumulative frequency for each of the three types of thinking, it can be seen that the predominant mode of thinking in the student reflections is principle-based thinking (PBT), followed respectively by case-based thinking (CBT) and experiential-intuitive thinking (EIT) in a descending order by cumulative frequency. More specifically, PBT, CBT and EIT respectively represent $74 \%, 22 \%$ and $4 \%$ of the sum of the cumulative frequencies for the three types of thinking. Principle-based thinking (PBT) is the highest form of thinking in physics (Schuster et al., 2007) and corresponds to a majority of activities in the course (ENGR 1215). 


\begin{tabular}{l} 
Code A-Mentioning PBT or any of its aspect(s)* without elaboration \\
\hline Examples: \\
1. Learned principle based thinking in the form of applying basic definitions towards problems both in class and tutorial as \\
well as homework. Also by graphical as well as mathematical representations of potential difference. (X12R3) \\
2. I learned another form of Ohms Law using current, resistivity and conductivity. This is principle based thinking. (X17R4)
\end{tabular}

Code B-Mentioning PBT or any of its aspect(s) ${ }^{*}$ with elaboration

\section{Examples:}

1. At home I used principle based thinking to further understand the right hand rule. I was having trouble grasping what to do with my hand to properly find the direction of the force. Now I know that you point your fingers in the direction of current then wrap your fingers in direction of magnetic field then your thumb is direction of magnetic force. (X3R7)

2. In lecture I used principle based thinking to find Faraday's law of induction. The law states that the induced electromotive force (emf) in a closed circuit is equal to the time rate of change of magnetic flux through the circuit $\mathcal{E}=-N d \Phi / d t$

Also in lecture we learnt about e-motional which has the electric force equal to magnetic force. As well as the emf is proportional to the rate of change of the magnetic flux. $\mathcal{E}=-d \Phi / d t, F_{E}=F_{B}$. (X3R9b)

\footnotetext{
\begin{tabular}{ll}
\hline & Code C-Applying PBT or any of its aspect(s) \\
\hline Examples: &
\end{tabular}

1. In the tutorial we developed an activity in groups. This was useful in taking a simulation and seeing how much information you can gather from it. Also it helped with working in groups and putting everyone's ideas together. In the simulation activity we developed a formula for the radius a charged particle will travel in a magnetic field. We did this by setting $F_{B}=F_{c}$ or $q v B \sin \theta=m v^{2} / r$ and solving for $r=m v / q B$ which shows as $v$ changes so does $r$." (X4R8)

2. $P B T$ - I learnt that units are very important in physics problems, understanding the units can help in solving problems as well as deriving formulas. In doing my homework questions. I was able to work out questions easier and faster. (X2R4)
Code D-Making meaning of PBT or any of its aspects"
- understanding/appreciating significance of PBT or its any aspect(s) ${ }^{*}$ or a feature of the course that helps in learning some aspect(s) of PBT
- critically assessing (sense-making) an answer obtained as a result of solving a problem using PBT
- gaining a useful insight for the future use
- retaining experience which may be useful in future
- learning a broader lesson
Examples:
1. In lecture I learnt that electron flow in a wire in a chaotic manner and that the flow of electrons is called the drift velocity and the flow is opposite to the electric field. This was demonstrated graphically. In reading my text book I learnt that all materials have resistivity and in doing homework question I found that resistivity increases with temperature. In doing the homework questions I discovered that drift velocity is very small meaning that it would take a lot longer time for an electron to travel around a circuit than I thought.

In an effort to make sense of his/her learning, then the student asks the following question about the drift speed of electrons in a circuit:

I'm confused what is actually going on in the circuit that makes things work? (X2R5)

2. From the book I learned about magnetic fields and forces. We learned that magnetic force $\boldsymbol{F}_{\boldsymbol{B}}=q \boldsymbol{v} x \boldsymbol{B}$ and this means that magnetic force is directly effected by the number (magnitude) of charge and their velocity and also magnetic field $B$. Also using principle based thinking we learn that SI unit for magnetic field is called Tesla $(T)=N / C . m / s-N / A . m$, and this way we can convert different units to tesla and using unit analysis we understand the meaning of this unit. (X7R6)

"Aspects of PBT: definitions, concepts, understanding or applications of principles, knowledge structure, representations (pictorial, physical, graphical and mathematical), order of magnitude calculations, dimensional (units) analysis.

Figure 1. Coding Scheme and example quotes from students' reflections for Principle-based Thinking (PBT). 
Examples:

1. This week I learned test-cased based thinking (torque). (X14R7)

2. Some case-based thinking to help calculate an expression for spherical capacitor. (X12R4)

\begin{tabular}{l} 
Code B-Mentioning CBT or any of its aspect(s) with elaboration \\
\hline Examples: \\
1. During one of our lectures this week we discussed potential energy. We used a model of gravitational force and created a \\
similar system with an electric field to find potential energy. I thought it was interesting that two different systems of forces \\
could have the same properties. (X1R3) \\
2. I learned (in the lab) that the magnetic field in a solenoid follows the right hand rule, where fingers curl in the direction of \\
current and thumb designates direction of magnetic field. We found this by observing the change in a compass when placed \\
inside the solenoid. We verified our finding by reversing the direction of the current and observing that the magnetic field \\
reversed the direction of the compass. This relates to my experiences in automotive mechanics because solenoids are commonly \\
used. (X5R8)
\end{tabular}

Code C-Applying CBT or any of its aspect(s) ${ }^{*}$

Examples:

1. During one of our lectures this week, we studied the effect of a magnetic field on a current carrying conductor. Depending how the wire is oriented in the field, the wire will experience a force caused by the field. We then looked at a coil of wires in a magnetic field . . From experience in mechanics, I knew how to calculate and apply the magnetic moment which is similar to finding normal force moments. Using the cross-product and right hand rules, I can find the magnitude and direction of the torque on a current carrying loop. (X1R8)

2. Biot-Savart Law [see figure], this law is used to calculate the magnetic field $(d B)$ at a point generated by a current I at a distance which was from $d B=k\left(I d l / r^{2}\right)$ which has a connection with Coulomb's Law: $E=k q / r^{2}$. q for Idl where I is always constant and $E$ with $d B$.

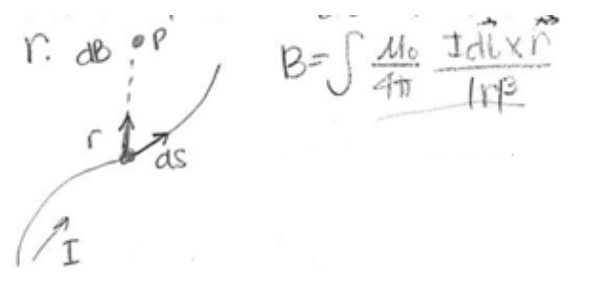

Then seeing this learning in the light of case-based thinking, the student further reflects:

Case based -this law could be equivalent to Coulomb's Law. Both of these laws state that as distance $r$ increases from a point (Point P) magnetic or electric field decreases. (X6R7)

Code D-Making meaning of CBT or any of its aspect(s)

- $\quad$ understanding/appreciating significance of CBT or its any aspect(s) ${ }^{*}$ or a feature of the course that helps in learning some aspect(s) of CBT

critically assessing (sense-making) an answer obtained as a result of solving a problem using CBT

gaining a useful insight for the future use

retaining experience which may be useful in future

- learning a broader lesson

\section{Examples:}

1. This week we discussed some questions relating to current and resistors. As I did some of the practice problems I had to use case based thinking to solve the problems using Keirkoffs[Kirchhoff's] rules. I obtained 3 equations to solve for current in a wire with multiple paths. I then used basic equation solving from mechanics to solve for the unknown variables in the equations. I found this to be very helpful because I can use methods obtained from other courses and I can apply them in different situations to solve problems. This method of thinking can help solve many problems because of the potential that applying basic problem solving has when faced with a complex question. (X1R7)

2. This situation can be understood using principle-based thinking, primarily, Lenz's law and Faraday's law. Lenz's law states that the direction of any magnetic induction effect will oppose the cause of the effect. Faraday's law states that the induced emf in a closed loop equals the negative of the time rate of change of the magnetic flux through the loop. The negative refers to the opposing nature of the effect to the cause. These two laws combined with the right hand rule allow me to understand this effect. Once I understand the situation I can just use the equations to understand any given problem quantitatively. The importance of knowing these laws is that I can apply them to any current carrying loop if there is a changing magnetic flux or current. (X10R8)

*Aspects of CBT: interpretation of a problem based on comparison with a past problem, generation of a solution based on a past problem (principles/procedure transfer or direct use of a previous case or example), understanding a situation based on a past situation, feature mapping adjusted for case differences or cross domain mapping (analogies).

Figure 2. Coding Scheme and example quotes from students' reflections for Case-based Thinking (CBT). 


\begin{tabular}{l}
\hline Code A-Mention of EIT without elaboration \\
\hline Examples: \\
\hline 1. The most kind of thinking I learned this week was experiential-intuitive thinking. (X8R2) \\
2. Learned: Principal Based Thinking and also Experiential Intuitive. (X7R2)
\end{tabular}

\footnotetext{
Code B-Mention of EIT with elaboration

Examples:

1. In the following example the student is reflecting on the fact that no work is done on a charged particle when it moves perpendicular to an electric field. Underline in the following quote has been added for emphasis.

My understanding of the concept was increased by seeing a model of the problem given in class. Seeing how the perpendicular work done though an electric field (displacement perpendicular to electric field) is zero and seeing that through the model has helped my intuitive thinking. (X5R3)

2. In lecture when discussing induced emf and electric fields we were asked whether the electric field would still be presentwhen the conducting ring was removed. See diagram. We than used our intuitive thinking in relation to our knowledge of gravitational field to conclude that even with the ring removed. The electric field would be present. Just like how the gravitational field would still be present even if you remove an object. (X9R9b)
}

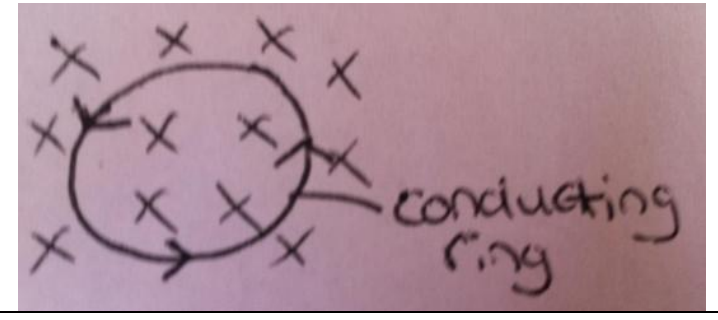

Code C-Applying EIT

No examples available to quote.

Code D-Making meaning of EIT

- critically assesses his/her own application of EIT

- $\quad$ gains a useful insight for the future use

- $\quad$ retaining useful experience which may be useful in future

- broader lesson

Example:

In the following quote, the student is evaluating his/her intuitive thinking about the magnetic field due to two currentcarrying conductors.

We learned about Biot-Savart Law, which is basically when a magnetic field is created by an electric current. At first, I thought I understood the concept, it seemed simple enough. However, when we applied the principle to a problem question, where we have two current carrying conductors which are parallel to one another and to find the resulting magnetic field and its direction between the two, I was confused. . . we had to figure out the magnetic field of both the conductors and subtract them to get a net field. (This confused me too because I thought since they were going in the same direction that they would both have the magnetic field going in the same direction and thus added them). However, I felt this was more intuitive thinking on my part, which was why I read from the textbook and learned otherwise this was wrong I figured this was important to figure out in order to tackle more difficult questions (such as if the current carrying conductor was not a straight line) in the future concerning Biot-Savart Law. (X14R8)

Figure 3. Coding Scheme and example quotes from students' reflections for Experiential-intuitive Thinking (EIT). 
Cumulative frequencies for three types of thinking

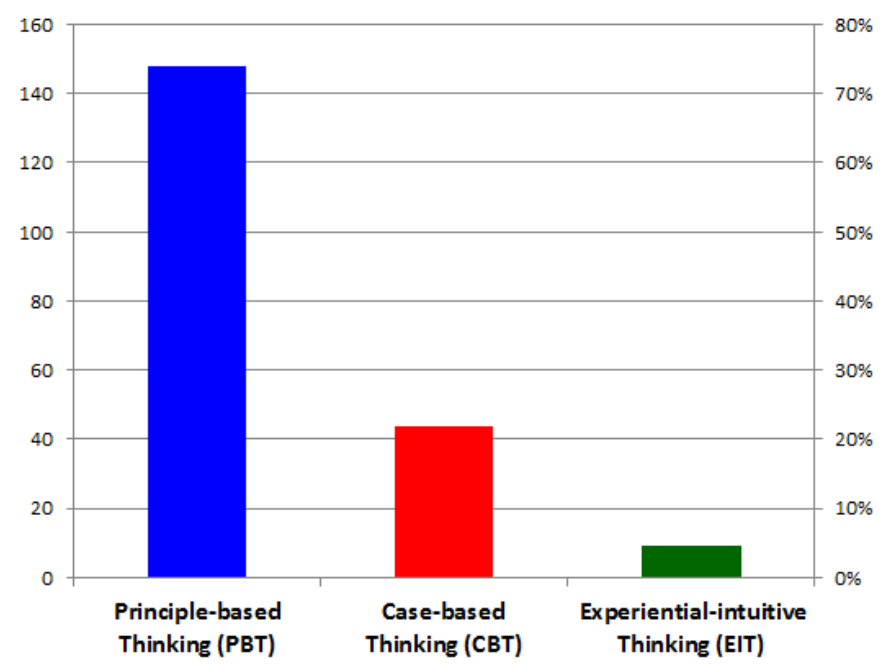

Figure 4. Cumulative frequencies of the three types of thinking covering all reflection reports by all participants over the whole semester-shown both as absolute value and percentage of the sum of the cumulative frequencies of the three types of thinking.

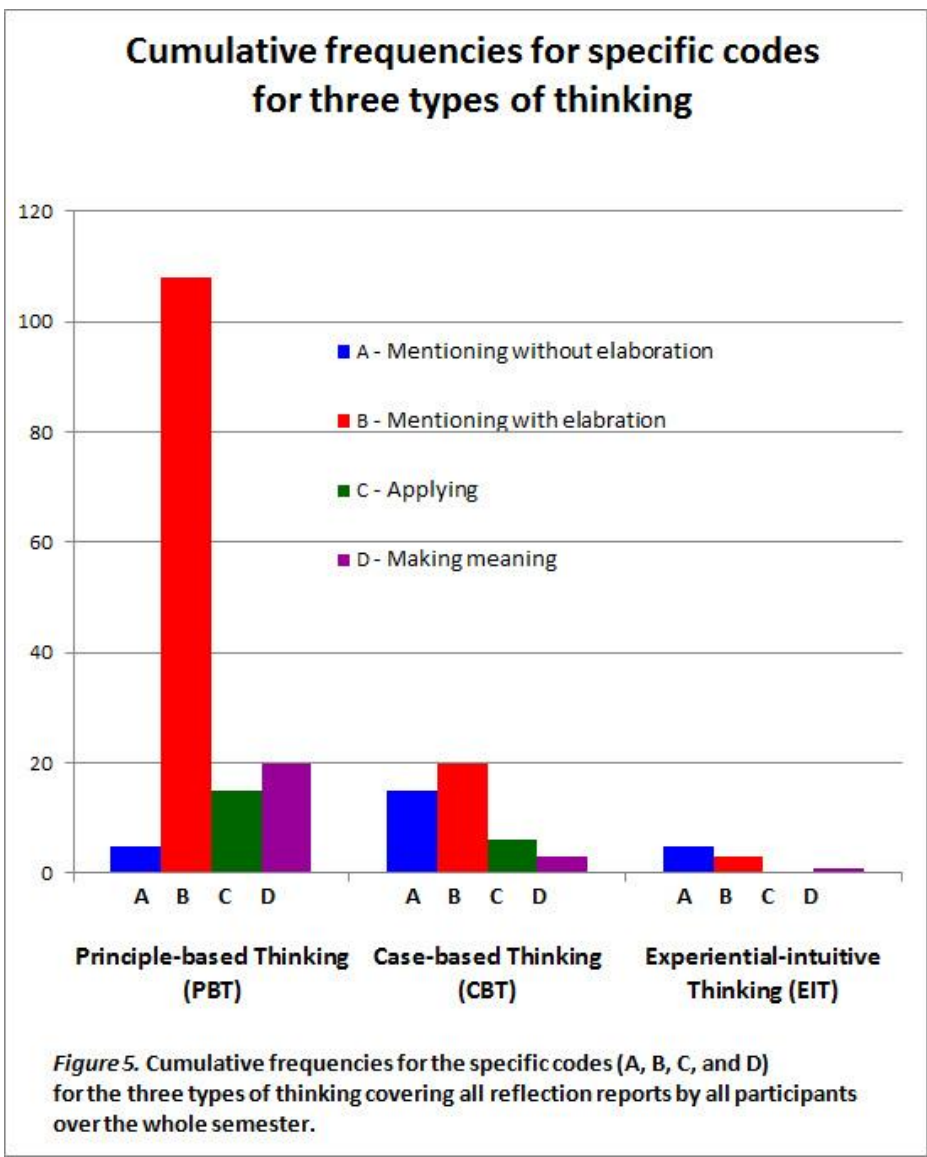


Therefore, predominance of PBT in the students' reflections is encouraging and demonstrates recognition by thestudents of the importance of PBT. Despite a considerably lower frequency for case-based thinking (CBT), the students' reflections generally indicate the potential of this mode of thinking in prompting them to make connections not only within the course, but also with the content of other courses. For example, the following is a representative quote from one student:

As I did some of the practice problems I had to use case based thinking to solve the problems using Keirkoffs [Kirchhoff's] rules. I obtained 3 equations to solve for current in a wire with multiple paths. I then used basic equation solving from mechanics to solve for the unknown variables in the equations. I found this to be very helpful because I can use methods obtained from other courses and I can apply them in different situations to solve problems. This method of thinking can help solve many problems because of the potential that applying basic problem solving has when faced with a complex question. (X1R7-means this quote is from reflection 7 of the student code named X1)

As this representative quote illustrates, case-based thinking helped students in solving problems, as well as in transfer of their prior learning. This is in line with Bassok and Holyoak's (1989) assertion that "an explicit hint to use an initial problem as a guide to help solve an analogous problem from a different domain increased the level of transfer. Without such external prompts, prior knowledge often remains 'inert"' (Whitehead, 1929 reprinted 1957 cited in Bassok \& Holyoak, 1989, p. 153). Bassok and Holyoak also mentioned that "One of the most persistent results in the studies of human problem solving is that experience with particular problems often yields little or no transfer to similar problems" (p. 153). So, the preceding quote also suggests that introducing students to case-based thinking helps them in transferring their experience with particular problems to other similar problems.

One interesting and surprising finding is that the students reflected very little on their experiential-intuitive thinking (EIT) even though this is a spontaneous form of thinking and would be expected to come to mind first in attempting conceptual questions, solving physics problems or understanding a multitude of phenomena such as the motion of charged particles in an electric field. One possible reason for the very few reflections on EIT may be the difficulty in reporting one's intuitive thinking as it represents an intermediate step between the cognitive stages of "I know what I am looking for" and "I know what to do" as reported by Baylor (2001, p. 238) on the basis of Fischbein (1975) and Schooler and Melcher (1995). Baylor (2001) also mentioned that the development of analytic thinking interferes with intuitive thinking until a certain level of expertise in a subject is achieved. Principle-based thinking (PBT) involves analytic thinking, so it is possible that the development of PBT in the students may be interfering with their intuitive thinking, thereby making it difficult to reflect on their intuitive thinking. Another possible reason may be that the topics of electricity and magnetism deal mainly with invisible objects and concepts (e.g., electron, proton, electric field, and electric potential) as opposed to topics of mechanics, which deal with objects and concepts that are related to everyday experience, such as ropes, inclined planes, velocity and force (Chabay \& Sherwood, 2006). Therefore, it may be an area of further research to explicitly prompt students to share their intuitive thinking in electricity and magnetism.

Now turning to the discussion of Figure 5, which depicts the cumulative frequencies of the specific codes within the three types of thinking, this figure shows that Code B (mentioning with elaboration) was the most frequent code in the students' reflections involving either principle-based thinking (PBT) or case-based thinking (CBT). More explicitly, this means that the students were elaborating on their experience of learning various aspects of PBT or CBT through different components of the course, mainly lecture, problem solving sessions and simulation activities. The analysis of these reflections shows that they were helpful to students in going beyond equations and formulas and in reinforcing the understanding of PBT and CBT. The next higher levels of reflections, in terms of complexity of thinking, involve independently applying (Code C) this learning of PBT or CBT to different situations like solving problems, and making meaning (Code D) of different aspects of PBT or CBT. As it can be seen from Figure 5, the frequencies of these higher-level codes are low compared to those of code B. More specifically, the frequencies of codes C and D are respectively $14 \%$ and $19 \%$ of the frequency of code B in case of PBT, while the corresponding ratios are $30 \%$ and $15 \%$ in case of CBT. In interpreting these results, the following factors must be kept in view: the participants were first-year students, this was the first run of the project, and the students were not guided to reflect at any particular level. One idea for the future is to provide sample reflections for all levels of thinking to students at the beginning of the semester. This will help them to see how to reflect at various levels, but 
will still maintain their freedom to reflect at any level of their choice. A similar discussion for experiential-intuitive thinking (EIT) has not been included here due to insignificant number of student reflections on this type of thinking. Possibly there is a need to provide more support to students to facilitate their reflection on EIT. In future, it may be viable to gain more insight into students' EIT by explicitly prompting them to share their EIT as stated earlier.

As was mentioned under Methodology, in order to gauge any shift in student thinking as a result of exposure to the thinking framework, the students were asked to provide a written response at the start of the course and then during the final examination to a question about how they solved physics problems. At the start, 13 of the 17 students were present when the question was asked and they all submitted their responses. The responses revealed that the majority of these students clearly had a formula-focused approach to problem solving as illustrated by one representative response quoted below:

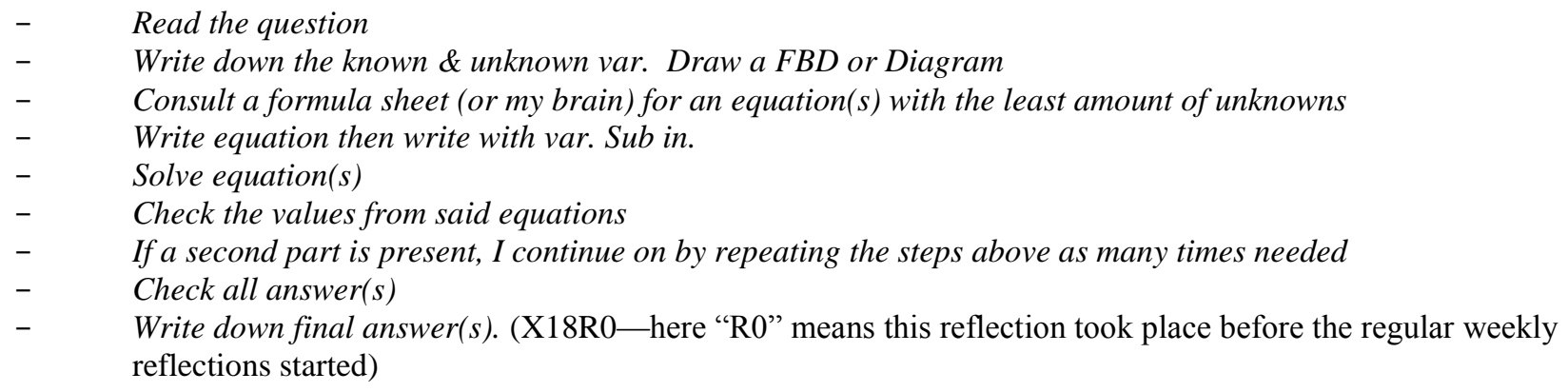

When the students answered almost the same question during the final examination, a positive shift to answers based on the thinking framework was clearly visible in generally all of the students. This is illustrated by the following representative quote from the student just quoted above. The quote also demonstrates progress in the student's thinking from the start to the end of the course.

That depends upon the question and the person's knowledge in the given subject. Through this course I have developed a principle based method of solving problems. This varies from my original method of solving problems. I used to write down the variables and find equations to solve. However, in ENGR 1215 I have started solving problems by reading and understanding the question so that I can then apply the appropriate principle. I can do this because I have great understanding of the principles taught in this course. From there I can apply the needed principles (not just formulas whole principles). This proves an effective method of solving problems. This is known as principle based thinking. However, if the a problem is difficult and I'm not just getting it, I use case based thinking and apply what happens in a similar case to that of the problem I am solving. If that doesn't work I ask for help. And that is how I solve physics problems. (X18R10)

This quote demonstrates a shift of the student's focus from equations to principles with a supporting role of case-based thinking in solving physics problems. This shift from equations to principles is desirable as Ellis and Turner (2003) have pointed out that experts focus on principles in solving problems while novice students focus on equations.

The following quote from another student's final examination reflects a similar shift from the formulafocused approach to the thinking framework based approach:

During the course I learned many new ways to solve physics problems. In the past I have always just looked at my givens then grabbed my formula sheet seeing which one fits. That method got me marks but not a true understanding of the real physics world. The way you taught this course I was forced to stop and think about how or where I was getting my answers from. I think that going through the kinds of thinking really helped my brain to develop an organized thinking manner that benefitted me greatly. I now approach problems by first reading then fully understanding the situation. Think about what principles apply. From 
there I will get the formula and proceed. Then check and see if my answer makes sense in the context of the problem. Thank you for this. I will never look at a physics problem the same way again! (X13R10)

Like the previous quote, this quote also highlights how the thinking framework has helped students in shifting focus from equations to principles in solving physics problems. Chabay and Sherwood (2004) mentioned that in first-year physics courses "Little attention is given to the larger goal of bringing students to see the unity of physics and the power of a small number of fundamental principles" (p. 2). Explicit focus on principles in principlebased thinking and the concomitant shift by the students from equations to principles seems to contribute well to the larger goal mentioned by Chabay and Sherwood (2004).

\section{CONCLUSION}

Findings of this study indicate that introducing first-year engineering students to a disciplinary thinking framework helped them to go beyond equations and formulas and begin to think like physicists by approaching physics problems and physical situations mainly in terms of underlying principles via principle-based thinking (PBT), and, to a lesser extent, in terms of prior knowledge of similar problems and situations via case-based thinking (CBT).

One surprising finding was that the students did not reflect much in their weekly reflection reports on their experiential-intuitive thinking as this is a spontaneous mode of thinking that would be expected to come to mind first in understanding a problem or a physical situation. A literature search revealed that the development of analytic thinking interferes with experiential-intuitive thinking (EIT); thereby making it harder to reflect on EIT (Baylor, 2001). One suggestion for a future study of this kind is to explicitly prompt students to reflect on their EIT, and also provide them with sample reflections to facilitate their reflection on EIT.

The majority of the students' reflections was at the elaboration level (code B) for both PBT and CBT and generally indicated a shift from a formula-focused approach to a principle-based approach in solving physics problems. One idea for the future is to provide sample reflections for all levels of thinking to students. This will help them to see how to reflect at various levels, but will still maintain their freedom to reflect at any level of their choice.

\section{ACNOWLEDGEMENTS}

The author thanks The Institute for Scholarship of Teaching and Learning and the Faculty of Teaching and Learning at Mount Royal University for the opportunity and support to carry out this study. The author would also like to thank the editor and the anonymous referees for their diligent review of this paper.

\section{AUTHOR INFORMATION}

M. Qasim Syed is currently an Associate Professor of Physics at Mount Royal University, Calgary, Alberta, Canada. He received his M.Sc. and Ph.D. in physics from the University of Calgary. He is also a 2010-Nexen Scholar of Teaching and Learning. E-mail: qsyed@mtroyal.ca

\section{REFERENCES}

Aamodt, A., \& Plaza, E. (1994). Case-based reasoning-Foundational issues, methodological variations, and system approaches. Ai Communications, 7(1), 39-59.

Anderson, L. W., Krathwohl, D. R., Airasian, P. W., Cruikshank, K. A., Mayer, R. E., Pintrich, P. R., Wittrock, M. C. (2001). A taxonomy for learning, teaching, and assessing: A revision of bloom's taxonomy of educational objectives, abridged edition. White Plains, NY: Longman.

Bagno, E., Eylon, B., \& Ganiel, U. (2000). From fragmented knowledge to a knowledge structure: Linking the domains of mechanics and electromagnetism. American Journal of Physics, 68(7), 516-526.

Bassok, M., \& Holyoak, K. J. (1989). Interdomain transfer between isomorphic topics in algebra and physics. Journal of Experimental Psychology: Learning, Memory, and Cognition, 15(1), 153-166. 
Baylor, A. L. (2001). A U-shaped model for the development of intuition by level of expertise. New Ideas in Psychology, $19(3), 237-244$.

Bloom, B. S. (1956). Taxonomy of educational objectives: The classification of education goals by a committee of college and university examiners. New York, NY: David McKay.

Chabay, R., \& Sherwood, B. (2006). Restructuring the introductory electricity and magnetism course. American Journal of Physics, 74(4), 329-336.

Chabay, R., \& Sherwood, B. (2004). Fundamental principles in introductory physics. Retrieved from http://matterandinteractions.org/Content/Articles/ChabaySherwoodFundamentals.pdf

Crouch, C. H., \& Mazur, E. (2001). Peer instruction: Ten years of experience and results. American Journal of Physics, 69(9), 970-977.

Derek Bok Center (Producer). (2007). Interactive teaching promoting better learning using peer instruction and just-intime teaching. [Video/DVD] Upper Saddle River, NJ: Pearson Prentice Hall.

diSessa, A. A. (1993). Towards an epistemology of physics. Cognition and Instruction, 102(2/3), 105-225.

Docktor, J. L., Mestre, J. P., \& Ross, B. H. (2012). Impact of a short intervention on novices' categorization criteria. Physical Review Special Topics--Physics Education Research, 8(2), 020102-1 to 020102-11.

Dufresne, R. J., Gerace, W. J., Leonard, W. J., Mestre, J. P., \& Wenk, L. (1996). Classtalk: A classroom communication system for active learning. Journal of Computing in Higher Education, 7(2), 3-47.

Ellis, G. W., \& Turner, W. (2003, June). Helping students organize and retrieve their understanding of dynamics. Paper presented at the 2003 American Society for Engineering Education Annual Conference and Exposition, Nashville, TN. (pp. 22-25).

Fagen, A. P., Crouch, C. H., \& Mazur, E. (2002). Peer instruction: Results from a range of classrooms. The Physics Teacher, 40(4), 206-209.

Ferguson-Hessler, M. G. M., \& de Jong, T. (1987). On the quality of knowledge in the field of electricity and magnetism. American Journal of Physics, 55(6), 492-497.

Fischbein, E. (1975). The intuitive sources of probabilistic thinking in children. Boston, MA: D. Reidel.

Fortus, D. (2009). The importance of learning to make assumptions. Science Education, 93(1), 86-108.

Gardner, H., \& Boix-Mansilla, V. (1994). Teaching for understanding-Within and across the disciplines. Educational Leadership, 51(5), 14-18. Retrieved from http://search.ebscohost.com/login.aspx?direct=true \&AuthType=ip,url,cookie,uid\&db=afh\&AN=9406020886\&s ite=ehost-live

Gire, E., Jones, B., \& Price, E. (2009). Characterizing the epistemological development of physics majors. Physical Review Special Topics--Physics Education Research, 5(1), 010103-1 to 010103-6.

Hake, R. R. (1998). Interactive-engagement versus traditional methods: A six-thousand-student survey of mechanics test data for introductory physics courses. American Journal of Physics, 66(1), 64-74.

Hestenes, D. (1987). Toward a modeling theory of physics instruction. American Journal of Physics, 55(5), $440-454$.

Kohl, P. B., \& Finkelstein, N. D. (2008). Patterns of multiple representation use by experts and novices during physics problem solving. Physical Review Special Topics —Physics Education Research, 4(1), 010111-1 to 010111-13.

Kolodner, J. L. (1992). An introduction to case-based reasoning. Artificial Intelligence Review, 6(1), 3-34.

Langer, J. A., Confer, C., \& Sawyer, M. (1993). Teaching disciplinary thinking in academic coursework. (No. 2.19). Albany, NY: National Research Center on Literature Teaching and Learning.

Lasry, N., Mazur, E., \& Watkins, J. (2008). Peer instruction: From Harvard to the two-year college. American Journal of Physics, 76(11), 1066-1069.

Leppävirta, J. (2012). The effect of naïve ideas on students' reasoning about electricity and magnetism. Research in Science Education, 42(4), 753-767.

Lindsey, B. A., Hsu, L., Sadaghiani, H., Taylor, J. W., \& Cummings, K. (2012). Positive attitudinal shifts with the physics by inquiry curriculum across multiple implementations. Physical Review Special Topics-Physics Education Research, 8(1), 010102-1 to 010102-8.

Lovatt, I., \& Syed, M. Q. (2014). Why was Kelvin's estimate of the earth's age wrong? The Physics Teacher, 52(5), 286287.

Mahajan, S. (2001). Physics students learn nothing, so try history of science. Retrieved from http://www.inference.phy.cam.ac.uk/sanjoy/ihpst/rote-physics.pdf

May, D. B., \& Etkina, E. (2002). College physics students' epistemological self-reflection and its relationship to conceptual learning. American Journal of Physics, 70(12), 1249-1258.

Mazur, E. (1997). Peer instruction: A user's manual. Upper Saddle River, NJ: Prentice Hall.

McDermott, L. C. (1993). How we teach and how students learn: A mismatch? American Journal of Physics, 61(4), 295298. 
McDermott, L. C., Heron, P. R., Shaffer, P. S., \& Stetzer, M. R. (2006). Improving the preparation of K-12 teachers through physics education research. American Journal of Physics, 74(9), 763-767.

McDermott, L. C., \& Shaffer, P. (1992). Research as a guide for curriculum development: An example from introductory electricity. Part I: Investigation of student understanding (erratum, ibid.61, 81, 1993). American Journal of Physics, 60(11), 994-1003.

Mc Dermott, L. C., Shaffer, P. S., \& Constantinou, C. (2000). Preparing teachers to teach physics and physical science by inquiry. Physics Education, 35(6), 411-416.

Meltzer, D., \& Manivannan, K. (2002). Transforming the lecture-hall environment: The fully interactive physics lecture. American Journal of Physics, 70(6), 639-654.

Miller, J. (1952). On the use of dimensional analysis in general physics. American Journal of Physics, 20(8), 520-521.

Miokovic, Z., Ganzberger, S., \& Radolic, V. (2012). Assessment of the university of Osijek engineering students' conceptual understanding of electricity and magnetism. Tehnicki Vjesnik-Technical Gazette, 19(3), 563-572.

Misic, T., Najdanovic-Lukic, M., \& Nesic, L. (2010). Dimensional analysis in physics and the Buckingham theorem. European Journal of Physics, 31(4), 893-906.

Modular approach to Physics. (n.d.). University of Calgary. Retrieved from http://canu.ucalgary.ca/

Moore, T. A. (2011). Online preface to six ideas that shaped physics. Retrieved from http://www.physics.pomona.edu/sixideas/sipref.htmlhttp://refworks.scholarsportal.info/refworks2/default.aspx? $\mathrm{r}=$ references|MainLayout::init\#

Nersessian, N. J. (1995). Should physicists preach what they practice? Science \& Education, 4(3), 203-226.

Novak, G. M., Gavrin, A., \& Wolfgang, C. (1999). Just-in-time teaching: Blending active learning with web technology. Upper Saddle River, NJ: Prentice Hall.

Oliveira, P. C., \& Oliveira, C. G. (2013). Using conceptual questions to promote motivation and learning in physics lectures. European Journal of Engineering Education, 38(4), 417-424.

Ornek, F., Robinson, W. R., \& Haugan, M. P. (2008). What makes physics difficult? International Journal of Environmental \& Science Education, 3(1), 30-34. Retrieved from http://search.ebscohost.com/login.aspx?direct=true \&AuthType=ip,url,cookie, uid\&db=ehh\&AN=32507421\&sit $\mathrm{e}=$ ehost-live

Pace, D., \& Middendorf, J. K. (2004). Decoding the disciplines: Helping students learn disciplinary ways of thinking. (New Directions for Teaching and Learning, 98) San Francisco, CA: Jossey-Bass.

Pepper, R. E., Chasteen, S. V., Pollock, S. J., \& Perkins, K. K. (2010). Our best juniors still struggle with Gauss's law: Characterizing their difficulties. AIP Conference Proceedings, 1289(1), 245-248.

Pescetti, D. (2008). Dimensional analysis and qualitative methods in problem solving. European Journal of Physics, 29(4), 697-707. Retrieved from http://stacks.iop.org/0143-0807/29/i=4/a=005

Pintrich, P. R. (2004). Understanding the development of student thinking in the college classroom. The Journal of Higher Education, 75(4), 476-480.

Schooler, J. W., \& Melcher, J. (1995). The ineffability of insight. In S. Smith, T. Ward, \& R. Finke (Eds.), The creative cognition approach (pp. 97-133). Cambridge, MA: MIT Press.

Schuster, D., Undreiu, A., \& Adams, B. (2007). Multiple modes of reasoning in physics problem solving, with implications for instruction. Physics Education Research Conference, 951(1), 184-187.

Schuster, D., \& Undreiu, A. (2009). Cognition of an expert tackling an unfamiliar conceptual physics problem. AIP Conference Proceedings, 1179(1), 265-268.

Sherin, B. L. (2001). How students understand physics equations. Cognition and Instruction, 19(4), 479-541.

Snyder, J. L. (2000). An investigation of the knowledge structures of experts, intermediates and novices in physics. International Journal of Science Education, 22(9), 979-992.

Syed, M. Q., \& Lovatt, I. (2014). An unusual exponential graph. The Physics Teacher, 52(5), 284-285.

Undreiu, A., Schuster, D., \& Adams, B. (2008). Reasoning modes, knowledge elements and their interplay in optics problem-solving. AIP Conference Proceedings, 1064(1), 211-214.

Van Heuvelen, A. (1991). Learning to think like a physicist: A review of research-based instructional strategies. American Journal of Physics, 59(10), 891-897.

Vosniadou, S. (2002). On the nature of naive physics. Reconsidering Conceptual Change: Issues in Theory and Practice, 61, 61-76.

Walsh, L., Howard, R., \& Bowe, B. (2007). An investigation of introductory physics students' approaches to problem solving. Level3, (Issue 5-June), 1-8.

Whitehead, A. N. (1957/1929). The aims of education. New York, NY: Macmillan. 